Relations industrielles

Industrial Relations

\title{
Arbitrage - Caractère non recevable d'une objection de non-arbitrabilité fondé sur la présentation " tardive " du grief, invoquée à l'audition seulement
}

Volume 18, numéro 3, juillet 1963

URI : https://id.erudit.org/iderudit/1021407ar

DOI : https://doi.org/10.7202/1021407ar

Aller au sommaire du numéro

Éditeur(s)

Département des relations industrielles de l’Université Laval

ISSN

0034-379X (imprimé)

1703-8138 (numérique)

Découvrir la revue

Citer ce document

(1963). Arbitrage - Caractère non recevable d'une objection de

non-arbitrabilité fondé sur la présentation « tardive » du grief, invoquée à

l'audition seulement. Relations industrielles / Industrial Relations, 18(3),

417-417. https://doi.org/10.7202/1021407ar
Résumé de l'article

Un tribunal d'arbitrage décide à l'unanimité qu'une partie à un litige ne peut soulever, à l'audition, l'objection préliminaire à l'effet que le grief n'est pas arbitrable, parce qu'ayant été soumis après l'expiration du délai prévu par la procédure de grief dans la convention collective, si elle ne l'a pas fait aux stages antérieurs de la procédure.
Tous droits réservés @ Département des relations industrielles de l’Université Laval, 1963
Ce document est protégé par la loi sur le droit d'auteur. L’utilisation des services d'Érudit (y compris la reproduction) est assujettie à sa politique d'utilisation que vous pouvez consulter en ligne.

https://apropos.erudit.org/fr/usagers/politique-dutilisation/ 


\title{
ARBITRAGE - Caractère non recevable d'une objection de non-arbitrabilité fondé sur la présentation «tardive» du grief, invoquée à l'audition seu- lement.
}

\author{
Un tribunal d'arbitroge décide à l'unanimité qu'une partie d̀ un litige ne peut \\ soulever, à l'audition, l'objection préliminaire d̀ l'effet que le grief n'est pas \\ arbitrable, parce qu'ayant été soumis après l'expiration du délai préru par \\ la procédure de grief dans la convention collective, si elle ne l'a pas fait aux \\ stages antérieurs de la procédure. ${ }^{1}$
}

Le procureur de l'employeur s'est objecté à l'arbitrabilité des griefs comme étont tordifs, suivant les termes de l'article 12, section $3 \mathrm{~d}$ de la convention collective de travail.

Le tribunal doit d'abord décider de cette objection préliminaire. Cet article 12, section $3 d$ se lit ainsi:-

« Si oucune demande écrite d'Arbitroge n'est reçue dans les quinze (15) jours ouvrables suivant la décision rendue à la $3 e$ étape, le grief sera reconnu comme étant réglé ou obandonné. \$

Les parties ont admis que la décision de la Compognie à la troisième étape, fut donnée ò l'Union, le 10 août 1962, par écrit dans une lettre signée par M. Laurent A. Corriveau, directeur des relations industrielles et du personnel de la Compognie (pièce U-5), et la demande écrite d'arbitrage faite por I'Union, fut en date du 28 septembre 1962, (pièce U-7).

L'Union a prétendu que l'Employeur avait en fait renoncé ò cette disposition particulière en procédant à la conciliation devant le conciliateur du Ministère du Travail sur cette question. Le conciliateur, M. J. Valentine, entendu comme témoin, a témoigné que la conciliation s'est faite devant lui, que les représentants de la Compagnie n'ont pas soulevé cette objection comme telle, et de toute façon, n'ont pas demandé que la conciliation procède sous réserve de leurs droits relativement aux dispositions de cet orticle particulier.

Vu cette preuve, c'est I'OPINION UNANIME des membres de ce tribunal que la Compognie a renoncé oux droits qu'elle ovait en vertu de cet article et POUR CES MOTIFS, l'objection préliminaire de non-arbitrabilité basée sur la tardivité faite par l'employeur, ne peut être reçue.

(1) Compagnie Miron Limitée et United Cement, Lime and Gypsum Workers International Union, local 515; Minıstère du Travail du Québec, Bulletin No. 1705-1963; Juge René Lippé, président, Me Raymond Tremblay, arbitre patronal, Me Jacques Chaloult, arbitre syndical. 